\title{
Research on the Cultivation of Students' Innovative Ability Based on Mathematical Modeling
}

\author{
Huajie Zhao \\ Xi'an Institute of Finance and Economics Xingzhi School, Xi'an, Shaanxi, China, 710038
}

Keywords: mathematical modeling; innovative ability; divergent thinking

\begin{abstract}
Mathematical modeling is an important way to cultivate students' innovative ability and comprehensive quality. This paper elaborates the influence of mathematical modeling on the cultivation of students' innovative ability, and analyzes in detail the methods of cultivating students' innovative ability based on mathematical modeling, so as to enable students to truly recognize the application of mathematics, develop their ability to analyze and solve practical problems, and cultivate their innovative practical ability.
\end{abstract}

\section{Introduction}

Mathematical modeling is a mathematical way of thinking. It uses mathematics language and methods to abstract and simplify the establishment of a mathematical method that can approximately describe and solve practical problems [1]. From the perspective of pedagogy, students establish the whole process of mathematical model, which can make them comprehensively apply the principles and methods of mathematics and related knowledge to solve practical problems and exercise their brain and hand skills, which helps to develop students' innovative and practical abilities. Mathematical modeling activities are a good carrier for improving students' mathematics literacy and cultivating their innovative and practical abilities, which are mainly composed of mathematical modeling course systems, mathematical modeling contests and training, and mathematical modeling knowledge lectures. The characteristics of the mathematical modeling activities include the practical problems, the extensive knowledge needs, the advanced technology application, and the various solutions. For this reason, carrying out mathematical modeling activities could play an important role in talent cultivation.

\section{The Steps and Processes of Mathematical Modeling}

\subsection{Mathematical modeling steps.}

Mathematical models can make certain necessary simplifying assumptions for specific objects, based on their internal laws, and appropriate mathematical tools to obtain the mathematical structure. The following figure 1 shows the modeling steps.

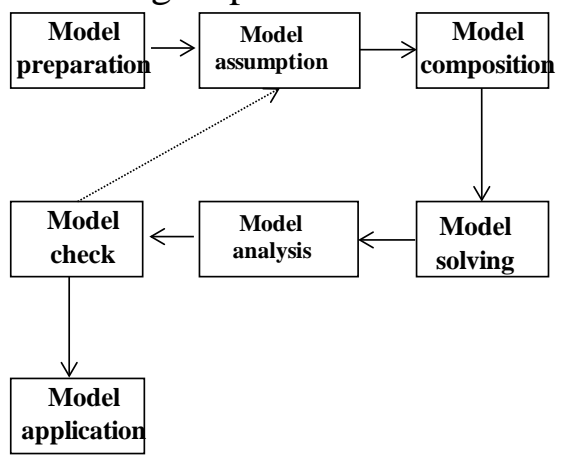

Fig.1 Mathematical modeling steps 


\subsection{Mathematical modeling processes.}

The model modeling processes are shown in Figure 2, in which the four stages realize the circulation of the mathematical model to the real object.

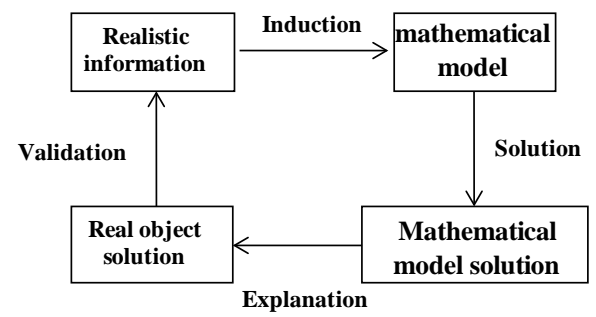

Fig.2 Mathematical modeling process

\subsection{An application case.}

Supposed Mr. Li borrows A Yuan from the bank, with the bank's monthly interest rate $R$, Mr. Li repays $m$ Yuan each month, and then the mathematical model for the general loan problem is showed below:

$$
\mathrm{a}_{\mathrm{n}}=(1+\mathrm{R})^{\mathrm{n}} \mathrm{A}-\mathrm{m} \frac{(1+\mathrm{R})^{\mathrm{n}}-1}{\mathrm{R}}, \mathrm{n}=0,1,2, \ldots
$$

Where $\mathrm{a}_{\mathrm{n}}$ indicates the amount of money owed by Mr. Li to the bank for the month $n$.

\section{The Effect of Mathematical Modeling on the Cultivation of Students' Innovative Ability}

\subsection{Cultivate students' intuition and divergent thinking.}

Mathematical modeling is an innovative process. In addition to imagination, insight, and judgment, which are the ability of image thinking and logical thinking, intuition and inspiration also play an important role. Intuition is a very keen comprehension, understanding, or inference of new things. Inspiration refers to guessing, thinking, or judgment that pops up in people's conscious or subconscious thinking. Both Intuition and inspiration have the main features of human creativity. Therefore, it is necessary to use intuition in the teaching of mathematical modeling to stimulate the students' inspiration.

From the practical significance of the problem, the mathematical modeling can be divided into several major categories. From the perspective of the problem solution, mathematical modeling can involve statistical analysis, neural networks, analytic hierarchy process, and many other methods. In choosing the method to solve the problem of mathematical modeling, first of all, it is intuitively to analyze and make decisions based on experience. It can be achieved the practicality of data processing, the innovation of model building, the accuracy of model representation, the rationality of the structure of the paper, and the objectivity of the language expression in model checking. Sometimes, new ideas and new methods in mathematical modeling come from divergent thinking, which is an important part of mathematics innovation. Strengthening the guidance of divergent thinking is also an important part of cultivating students' creative thinking.

\subsection{Cultivate the imagination and insight of students.}

Using mathematical modeling methods to solve practical problems, the first is to use mathematics to describe the problem, and to construct a model, then using a mathematical tool to solve the established model. Use mathematical language to describe problems, including model assumptions, model construction, which requires not only extensive knowledge of mathematics, practical knowledge, and experience, but also requires a great deal of imagination and keen insight. Imagination refers to people who, based on their original knowledge, compare, reorganize, and process the newly perceived image and the image in memory to create a new image, which is an 
image thinking activity.

\subsection{Develop students' hands-on and self-evaluation skills.}

Mathematical model solving, model checking, including data processing of practical problems in the modeling process are inseparable from computer technology, such as the use of mathematical software such as Lingo, Mathematical, it also need to carry out reasonable development to play its due role in the solution of practical problems. In the training of mathematical modeling, students are trained to use their existing knowledge and experience to consciously test and judge the thinking process or results of themselves or others. The self-reporting, analysis of mistake cases in the modeling, and evaluation ideas are used to cultivate students' awareness of self-evaluation. This is the process of self-regulation, self-improvement, and self-development of the cognitive structure, which is also a necessary link in cultivating innovation capabilities.

\subsection{Develop students’ team awareness and collaboration skills.}

The completion of mathematical modeling requires the cooperation of the members of the group, so that the students' spirit of cooperation and cooperation is also fostered, and the ability to communicate and express can also be improved. Through the development of modeling activities, teachers' teaching and scientific research level has been promoted continuously, and the modeling thought of modeling should be added to the professional needs, and the new teaching methods are tried, the students' consciousness of mathematical application is cultivated in the teaching, and the mathematics accomplishment of higher vocational students is improved.

\subsection{Promote the cultivation of students' innovative ability.}

Mathematical modeling is a course that places great emphasis on theory and practice. It is different from traditional mathematics courses, which focuses on rigorous mathematics theory and skills training for students, and regards the cultivation of students' innovative ability as the main task. Mathematical modeling is the use of mathematical language and tools to translate some of the real world information into a product of induction. After the mathematical model is deduced, solved and inferred, through mathematical analysis, forecasting, decision-making or control, and then through deduction and interpretation, it returns to the real world and finally completes the cycle between theory and practice.

From the perspective of mathematics methodology, mathematical modeling is a method of transformation, which has the characteristics of connection with reality and abundant cases [2]. It is the best combination of improving mathematical knowledge and application ability, and an effective way to cultivate students' innovative ability. From the perspective of mathematics education philosophy, mathematical modeling is the perfect combination of the social goals of mathematics education and the goals of mathematics education.

\section{Methods and Approaches to Cultivate Students' Innovative and Practical Ability Based on Mathematical Modeling Activities}

\subsection{Strengthen the construction of mathematical modeling courses.}

First of all, schools should draw lessons from the establishment of mathematical modeling courses, and build module plus application mathematical modeling curriculum system for the specific conditions of the school [3]. In the course of curriculum construction, the introduction of new teaching methods, teaching means and teaching tools, the application of mathematics throughout the teaching, focusing on the cross integration of professional courses, continuous infiltration of mathematical modeling ideas, through the modeling curriculum to build scientific and innovative personnel training model. 


\subsection{Establish a complete training system of mathematical modeling contest.}

The National Undergraduate Mathematical Contest in modeling is a good carrier to cultivate students' innovative and practical ability, and establish a relatively perfect training system for modeling competition [4]. As holding regular public welfare mathematical modeling knowledge lectures, which popularizes the knowledge of mathematical modeling to students, compiling the school-based training materials for mathematical modeling, explaining the relevant knowledge of modeling for students, focusing on the training of students in the summer vacation time, and paying attention to the training of modeling questions. Through this relatively perfect modeling training, students can understand the knowledge of mathematical modeling and improve the modeling ability quickly.

\subsection{Focus on accumulation and optimize knowledge structure.}

Basic knowledge is the source of building innovation capabilities. The more basic knowledge of mathematics, the wider the scope of association, analogy, and divergence is. And the more opportunities to discover new ideas and new conclusions will have the greater the ability to innovate. Therefore, in mathematics modeling teaching, it is necessary to implement the principles of permeability, hierarchy, application, and practicality to help students build innovative capabilities and optimize students' mathematical knowledge structure. And change students' habits of problem solving based on theorems, and help them to build the ability to solve practical problems.

\subsection{Attach importance to cognitive process.}

In mathematics modeling teaching, students should be given more time for independent thinking, and providing students with free and imaginative and free space to play, motivating students to be suspicious in doubt, and questioning the boundary conditions of mathematical theory and mathematical methods, and guiding them to discover potential solutions of difficult problems.

\section{Summary}

Mathematical models not only help students truly recognize the applicability of mathematics, develop students' ability to analyze and solve practical problems, but also help students develop innovative practical abilities. By optimizing the knowledge structure, we should pay attention to the cognitive process, design teaching, promote students' divergent thinking and intuitive thinking, and cultivate innovative character. The mathematical model is not only a simple abstraction of practical problems, but also a sublimation of the essential characteristics of describing practical problems in mathematical language. Therefore, mathematical modeling is an important way to cultivate students' innovative ability and comprehensive quality.

\section{References}

[1] Zhu Hong, Fu Jun. Mathematics Teaching and the Cultivation of Mathematical Thinking Quality[J]. Journal of Anshan Teachers College, 2004(6), p.28

[2] Peng Linping. Improving Students' Quality and Innovation Ability Based on Mathematical Modeling Activities[J]. Higher Education Review,2015(18), p.69

[3] Jiang Qiyuan, Xie Jinxing. Mathematical Model[M]. Beijing: Higher Education Press, p.17

[4] Li Daqian. Integrate Mathematical Modeling Ideas into Mathematics Class Courses[J]. Chinese University Teaching, 2016 (1), p.17 